\title{
Volatile and sensory evaluation of Mexican Fresco cheese as affected by specific wild Lactococcus lactis strains
}

\author{
Ricardo Reyes-Díaz, ${ }^{1}$ Aarón F. González-Córdova, ${ }^{1} \odot$ María del Carmen Estrada-Montoya, ${ }^{1}$ \\ José I. Méndez-Romero, ${ }^{1}$ Miguel Angel Mazorra-Manzano, ${ }^{1} \odot$ Herlinda Soto-Valdez, ${ }^{2}$ \\ and Belinda Vallejo-Cordoba ${ }^{1 *}$ (i) \\ ${ }_{1}^{1}$ Laboratorio de Química y Biotecnología de Productos Lácteos, Coordinación de Tecnología de Alimentos de Origen Animal (CTAOA), and \\ ${ }^{2}$ Laboratorio de Envases de Alimentos, Coordinación de Tecnología de Alimentos de Origen Vegetal (CTAOV), Centro de Investigación en \\ Alimentación y Desarrollo A.C. (CIAD), Carretera Gustavo Enrique Astiazarán Rosas \#46, La Victoria, Hermosillo, Sonora, 83304, México
}

\begin{abstract}
Lactococcus lactis is the lactic acid bacteria most frequently used for the production of cheese starter cultures, mainly because of their efficient production of aroma compounds. However, commercial cultures do not always produce the typical aroma notes of artisanal raw-milk cheeses. Thus, the objective of this study was to characterize the volatile compounds generated by wild L. lactis strains in Mexican Fresco cheese made with pasteurized milk. Four strains of wild L. lactis were evaluated for their aroma production in Mexican Fresco cheese using sensory and instrumental analysis. The aroma profiles were evaluated by descriptive sensory analysis. Volatiles were determined by solid-phase microextraction and gas chromatography-mass spectrometry. Principal component analysis was applied to interpret analytical and sensory data. Mexican Fresco cheese aroma was described as milkfat, yogurt, yeasty, barny, dirty socks, and Fresco cheese. Cheese with $L$. lactis strains R7 or B7 were most similar to commercial raw milk Fresco cheese in all aroma descriptors. Volatiles identified in all cheeses were esters, acids, alcohols, ketones, and aldehydes, but the main differences were found for total volatile relative abundance. Also, volatile concentrations $(\mu \mathrm{g} / \mathrm{g})$ in commercial raw milk Fresco cheese and cheeses made with L. lactis R7 or B7 were 4 methyl esters [C4 (4.15 vs. 5.47-13.74), C6 (0.12 vs. $1.53-15.34)$, C8 (1.06 vs. $0.32-6.65)$, and $\mathrm{C} 10$ (0.62 vs. $0.41-3.74)], 7$ acids [C4 (1.92 vs. 0.30-9.29), C6-C10 (0.05-4.48 vs. 0.11-30.45), and C12 (0.13 vs. $0.28-0.30)], 2$ alcohols [(3-methyl-1-butanol (3.48 vs. $3.4-13.13)$ and phenylethyl alcohol (0.10 vs. $0.63-2.04)]$, and 1 ketone (acetoin; 1.22 vs. $0.28-0.99$ ). The first 3 principal components explained $78.2 \%$ of
\end{abstract}

Received June 28, 2019.

Accepted September 28, 2019.

*Corresponding author: vallejo@ciad.mx the total variation and clearly distinguished 3 main groups. Cheese made with L. lactis $\mathrm{R} 7$ was classified in the same group as key compounds associated with Fresco cheese aroma and show potential as a starter in Mexican Fresco cheese manufacture.

Key words: Mexican Fresco cheese, Lactococcus lactis, solid-phase microextraction, aroma compound

\section{INTRODUCTION}

Fresco cheese is the most popular cheese variety consumed in Mexico and in other Latin American countries (González-Córdova et al., 2016). Moreover, it is the most popular Hispanic-style cheese consumed in the United States (van Hekken and Farkye, 2003). Because the artisanal Fresco cheese is produced from raw milk and subsequently consumed without a ripening process, it is not safe for human consumption (Torres-Llanez et al., 2006). Mexican Fresco cheese made from pasteurized milk results in a product of better sanitary quality; however, pasteurization affects its sensory characteristics because it eliminates the native microflora present in milk that confers such characteristics. This problem may be solved by adding appropriate cultures to cheese milk after pasteurization. Although commercially available starters have been used to solve this problem, the sensory properties of the product do not resemble those of the artisanal cheese. Thus, the microflora of artisanal Mexican Fresco cheese was characterized as a first step toward the development of starter cultures. The microflora of this cheese is well characterized (Torres-Llanez et al., 2006; Renye et al., 2008); however, its typical volatile and aroma profiles have not been reported.

Volatile aroma compounds in cheese are the result of different metabolic pathways such as glycolysis, lipolysis, and proteolysis of milk components, which are mediated by different enzymatic mechanisms (Aydin, 2017). Furthermore, it has been reported that the catabolism of AA is the most important pathway for 
volatile production (Ganesan and Weimer, 2017). Also, because AA conversion is strain specific, this highlights the importance of strain selection for industrial fermentations where good and distinct aromas are the main objective (van de Bunt et al., 2014).

One of the dominating LAB group in artisanal Mexican Fresco cheese is Lactococcus lactis (Torres-Llanez et al., 2006). These organisms are frequently used in cheese starter cultures because of their high efficiency for producing aroma compounds. In fact, wild-type strains generally produce specific aromas quite distinct from those produced by industrial strains (Ayad et al., 1999; Gutiérrez-Méndez et al., 2008; Picon et al., 2019). Thus, studying the aroma profiles given by wild-type lactococci in Mexican Fresco cheese may be of interest as a first step toward the development of a starter culture that would allow cheese manufacture from pasteurized milk with typical aroma notes. Furthermore, to the best of our knowledge, the aroma of artisanal Mexican Fresco cheese has not been characterized by descriptive sensory and volatile analyses.

Thus, the objective of this study was to characterize volatiles generated by wild L. lactis strains in Mexican Fresco cheese by solid-phase microextraction (SPME) GC-MS. Additionally, volatiles responsible for specific aroma descriptors were determined by relating quantitative sensory and GC data by multivariate analysis of commercial and prepared cheeses with specific wild-type L. lactis strains in an attempt to explore new distinctive aroma profiles that may lead to the development of a suitable starter culture.

\section{MATERIALS AND METHODS}

\section{Starter Cultures}

Four wild L. lactis strains (R7, B7, Q1, and Q5) were obtained from the dairy laboratory collection of Centro de Investigación en Alimentación y Desarrollo, A.C., located in Hermosillo, Sonora, Mexico. These strains were isolated from beetroot (B7) and raw milk artisanal dairy products (R7, Q1, and Q5) and were selected for producing typical lactic aromas (yogurt-like and Fresco cheese-like) in fermented milk (Gutiérrez-Méndez et al., 2008).

Lactococcus lactis strains maintained in glycerol at $-80^{\circ} \mathrm{C}$ were reactivated by inoculating $100 \mu \mathrm{L}$ into 10 $\mathrm{mL}$ of sterile M17 broth supplemented at $5 \%$ (vol/vol) with a sterile solution of lactose $(10 \% \mathrm{wt} / \mathrm{vol})$ and incubated at $30^{\circ} \mathrm{C}$ for $24 \mathrm{~h}$. Fresh cultures were obtained by repeating this procedure twice. To minimize carryover from the culture broth during inoculation, cell suspensions $(5 \mathrm{~mL})$ were harvested by centrifugation $\left(6,000 \times g, 10 \min , 4^{\circ} \mathrm{C} ; 5417 \mathrm{R}\right.$, micro-centrifuge, $\mathrm{Ep}-$ pendorf AG, Hamburg, Germany), washed twice, and resuspended in $5 \mathrm{~mL}$ of $0.32 \mathrm{mM} \mathrm{Na} \mathrm{NPO}_{4}(\mathrm{pH} 7.2$ ). Resuspended washed cells were inoculated $(1 \%)$ into sterilized $\left(100^{\circ} \mathrm{C}\right.$ for $\left.10 \mathrm{~min}\right)$, reconstituted $(11 \%$, wt/ vol) nonfat dry milk. The inoculated milk with each strain was incubated at $32^{\circ} \mathrm{C}$ during $8 \mathrm{~h}$ to reach $10^{7}$ $\mathrm{cfu} / \mathrm{mL}$, as enumerated on M17 agar containing 5\% ( vol/vol) of a sterile solution of lactose $(10 \% \mathrm{wt} / \mathrm{vol})$. These fermented milks were used as starter cultures for the cheese manufacture.

\section{Cheese Manufacture}

Cheeses were made according to the traditional method for Mexican Fresco cheese manufacture reported by Torres-Llanez et al. (2006), except that milk was pasteurized. All the tools were previously sterilized and the operations were performed adjacent to a flame. Raw milk collected from a local dairy farm was used for cheese manufacture and was pasteurized at $63^{\circ} \mathrm{C}$ for 30 min. Pasteurized milk was cooled to 32 to $34^{\circ} \mathrm{C}$ and maintained at this temperature. Cheeses were made by adding starter culture $(2 \%, \mathrm{vol} / \mathrm{vol}$, of each starter culture) to the milk (10 L for each batch), which was ripened for $60 \mathrm{~min}$. Then, milk was coagulated at $32^{\circ} \mathrm{C}$ with the addition of commercial calf rennet (strength 1:10,000; Industrias Cuamex, Iztapalapa, Mexico) as suggested by the supplier $(15 \mathrm{~mL}$ per $100 \mathrm{~L}$ of milk, diluted into $100 \mathrm{~mL}$ of purified water). To get bacteriafree rennet, it was filter-sterilized through a $0.22-\mathrm{mm}$ pore membrane (Millex-GS, Millipore, Bedford, MA), then was added to the milk and mixed briefly. Milk containers were set to rest for about 90 min until a firm coagulum was formed. Afterward, the coagulum was cut with a sterile stainless-steel curd cutter into small pieces (approximately $0.5 \times 0.5 \times 0.5 \mathrm{~cm}$ ) to increase the expulsion of moisture from the curd. The curd was set to rest (15-30 min), then the whey was drained off and salt $(30 \mathrm{~g} / 10 \mathrm{~L})$ was added. The curd was homogenized into molds and was set to rest in refrigeration during $12 \mathrm{~h}$. The cheeses were removed from molds, packaged, and stored at $4^{\circ} \mathrm{C}$ during $5 \mathrm{~d}$ before testing.

In total, 2 batches of the different Mexican Fresco cheeses with $L$. lactis strains were made $(1.5 \mathrm{~kg}$ cheeses, 2 replicates per batch): R7, B7, Q1, and Q5. A control cheese $(\mathbf{C O N})$ without a starter was also made. Additionally, 6 commercial Mexican Fresco cheeses (CRMFC) made from raw milk (verified by the alkaline phosphatase test) were purchased from different manufacturers at the local market in Hermosillo, Sonora, Mexico. All the cheeses were stored at $-20^{\circ} \mathrm{C}$ until analyses. 


\section{Physicochemical and Microbiological Analyses}

Physicochemical parameters were determined according to standard methodologies (AOAC International, 2000). Cheese milk was analyzed for TS (method: 925.23), protein (method: 991.20), fat (method: 989.04), ash (method: 945.46), acidity (method: 947.05), and $\mathrm{pH}$ by using a $\mathrm{pH}$ meter (Microprocessor $\mathrm{pH}$ meter, Hanna Instruments, Woonsocket, RI). After cheese manufacture and before storing, cheeses were analyzed for moisture (method: 948.12), total protein (method 920.123), ash (method: 935.42), pH (as in cheese milk), and fat (method: modified Babcock, B12.1; Marth, 1978). Furthermore, salt $(\mathrm{NaCl})$ was determined by following the methodology reported by Marth (1978). The CRMFC were also analyzed for moisture, protein, fat, ash, and salt contents.

For microbiological analysis, pasteurized cheese milk $(10 \mathrm{~mL})$ or 5 -d-old cheese $(10 \mathrm{~g})$ samples were homogenized with $90 \mathrm{~mL}$ of sterilized phosphate buffer. Decimal dilutions were prepared in sterile phosphate buffer and plated in duplicates on M17 agar for $48 \mathrm{~h}$ at $30^{\circ} \mathrm{C}$.

\section{Sensory Analysis}

Aroma intensity in Fresco cheese samples (10 g) was evaluated by using quantitative descriptive analysis as reported by Meilgaard et al. (1999). From a total of 22 candidates, a group of 10 subjects were selected by sequential analysis. All the candidates were assessed for their ability to detect aroma differences by applying 13 triangle tests. After describing the aroma profile of Mexican Fresco cheeses, specific aroma descriptors were defined according to notes derived by the selected panel panelists.

Training started by holding discussions between the panel leader and the panelists to understand the intensity scale and the use of the reference samples. Panelists evaluated aroma intensity by using a $15-\mathrm{cm}$ attribute reference scale (from $0=$ imperceptible, the absence of the aroma to $15=$ extremely pronounced), the same aroma intensity of a reference sample defined for each descriptor. Six reference samples were used: heavy cream for "milkfat," unflavored yogurt for "yogurt," raw yeast dough for "yeasty," stable hay for "barny," CRMFC for "Fresco cheese," and CRMFC stored at $30^{\circ} \mathrm{C}$ for $3 \mathrm{~h}$ for "dirty socks." Training began by presenting panelists with the end-point references. Aroma notes associated with samples were described by the panel leader, and the technique to be used in the testing session was explained. At every training session, panelists were given samples of commercial Mexican Fresco cheeses and instructed to recognize and record the aroma intensity perceived. All evaluations were performed in individual booths under red light, and 6 samples randomly coded with a 3-digit number to remove bias were used at every testing session. To assess the performance of the trained panelists, 6 coded samples were tested and analyzed by using ANOVA. The panel was considered trained when reproducible responses (no statistical differences at $\alpha=0.05$ ) among panelists were given for each descriptor. Once the panel was trained, samples were tested for each type of Mexican Fresco cheese $(n=4)$. Panelists were instructed to only smell the samples since the safety of the commercial raw milk cheeses could not be ensured.

\section{Analysis of Volatile Compounds by Headspace SPME and GC-MS}

Volatiles in cheese samples were assessed by using headspace (HS) SPME and GC-MS. Volatiles were analyzed by placing $3 \mathrm{~g}$ of finely grated cheese, $7 \mathrm{~mL}$ of a saturated $\mathrm{NaCl}(28 \% \mathrm{wt} / \mathrm{vol})$ solution, and $5 \mu \mathrm{L}$ of an internal standard (nonanoic acid ethyl ester at $1 \mu \mathrm{L} /$ $\mathrm{mL}$ in methanol) in screw-capped glass vials $(20 \mathrm{~mL}$, $22.75 \times 75 \mathrm{~mm} ; 18 \mathrm{~mm}$ cap) for headspace analysis. Then, they were tightened by $18 \mathrm{~mm}$ steel-magnetic screw caps with polytetrafluorethylene/silicone septa. The sealed vials were placed in a PAL auto sampler system (GC Sampler 80, Agilent Technologies, Basel, Switzerland). Before SPME extraction, samples were allowed to equilibrate at $70^{\circ} \mathrm{C}(150 \mathrm{rpm})$ for $30 \mathrm{~min}$. After this period, a 75- $\mu \mathrm{m}$ CAR-PDMS fiber (Supelco Co., Bellefonte, PA) was exposed to the sample headspace while shaking $(150 \mathrm{rpm})$ at $70^{\circ} \mathrm{C}$ for $60 \mathrm{~min}$. Then the fiber was withdrawn into the needle of the SPME device and immediately desorbed at $250^{\circ} \mathrm{C}$ for $10 \mathrm{~min}$ in splitless mode into the injection port of a GC/MSD System (Agilent Technologies 7890A/5975C, Santa Clara, CA). The injector was provided with an inlet liner $(78.5 \mathrm{~mm} \times 6.5 \mathrm{~mm}$ o.d. $\times 0.75 \mathrm{~mm}$ i.d., SigmaAldrich, St. Louis, MO) special for SPME. Helium (ultra-high purity) was used as the gas carrier at a flow of $1.5 \mathrm{~mL} / \mathrm{min}$. The compounds were separated by a high-polarity DB-WAX column (60 m length, $0.25 \mathrm{~mm}$ i.d., $0.25-\mu \mathrm{m}$ film thickness, Agilent J\&W Scientific) with a carrier gas at $1 \mathrm{~mL} / \mathrm{min}$. The oven temperature was held at $45^{\circ} \mathrm{C}$ for $12.5 \mathrm{~min}$, increased to $114^{\circ} \mathrm{C}$ at a rate of $4^{\circ} \mathrm{C} / \mathrm{min}$, held at $114^{\circ} \mathrm{C}$ for $6 \mathrm{~min}$, then increased to $143^{\circ} \mathrm{C}$ at a rate of $7^{\circ} \mathrm{C} / \mathrm{min}$, held at $143^{\circ} \mathrm{C}$ for $15 \mathrm{~min}$, and finally increased to $165^{\circ} \mathrm{C}$ at a rate of $15^{\circ} \mathrm{C} / \mathrm{min}$, held at $165^{\circ} \mathrm{C}$ for $15 \mathrm{~min}$. The volatile compounds were identified by comparing their spectra with those from the National Institute of Standards and Technology MS library (v. 2.0 g., 2011) and the retention times and ion 
spectra of analytical standards (PolyScience Co., Niles, IL).

\section{Statistical Analysis}

Data were analyzed by a one-way ANOVA and groups were considered significantly different when $P \leq 0.05$. Fisher's least significant difference multiple-comparison test was used to assess differences among averages. Principal component analysis (PCA) was performed to relate analytical and sensory data. Clusters were determined by the k-means clustering analysis. All the statistical analyses were performed by using the NCSS2007 statistical software (Hintze, 2006).

\section{RESULTS AND DISCUSSION}

\section{Cheese Manufacture and Physicochemical Analyses}

Physicochemical parameters for all cheeses and cheese milk after $5 \mathrm{~d}$ of refrigerated storage are reported in Table 1. No statistical differences $(P>0.05)$ were observed in the composition and physicochemical parameters among pasteurized cheeses, except for $\mathrm{pH}$. The Q5 showed the lowest $\mathrm{pH}$, followed by R7, Q1, and $\mathrm{B} 7$. The CRMFC pH $(5.35)$ was significantly $(P<0.05)$ lower than that in CON (6.43), B7 (6.37), and Q1 (6.18) but not different $(P>0.05)$ from R7 (5.58) and Q5 (5.35). The low $\mathrm{pH}$ value of CRMFC may be due to the fact that these commercial cheeses are made from raw milk and this may allow the growth of lactose fermenting microorganisms such as lactic acid bacteria (LAB), among others. It is important to highlight that the $\mathrm{pH}$ of cheeses R7 and Q5 were not significantly different $(P$ $>0.05)$ from that of CRMFC. In fact, these $\mathrm{pH}$ values were similar to the $\mathrm{pH}$ of 5.6 reported for raw milk Mexican Fresco cheese after $10 \mathrm{~d}$ of refrigerated storage (Torres-Llanez et al., 2006). Thus, these 2 strains appear to have a high acidifying capacity in cheeses.
In previous studies, it was reported that most strains isolated from traditional raw milk products ( $\mathrm{R} 7$ and Q5), had fast lactose fermentation, whereas nondairy strains (B7) were slow lactose fermenters (GutiérrezMéndez et al., 2008).

Cheeses were no significantly different $(P>0.05)$ for moisture, TS, protein, ash, and $\mathrm{NaCl}$ content (Table 1). Nevertheless CRMFC were significantly lower in fat $(18.8 \%)$ than cheeses made with pasteurized milk (21.8-22.8\%). These differences may be attributed to the composition of cheese milk, which was high in fat and approaching the upper limit reported for cow milk (3.3-4.7\%; Fox et al., 2017). Nevertheless, it is important to mention that CRMFC samples showed significant differences $(P<0.05)$ in chemical composition due to the lack of standardization of artisanal cheese manufacture.

\section{Microbiological Analyses}

Lactic acid bacteria counts on M17 agar for R7, B7, Q1, and Q5 cheeses reached 7.3 to $7.9 \mathrm{log} \mathrm{cfu} / \mathrm{g}$ after a $5 \mathrm{~d}$ of storage at refrigeration temperature. Thus, the viability of the starter culture was confirmed. On the other hand, for CRMFC, microbiological analysis was not carried out because the microbiological composition of these type of cheeses was previously reported (Torres-Llanez et al., 2006). Indeed, in those studies, L. lactis was the most numerous species in Mexican Fresco cheese made out of raw milk, since from the total isolates obtained on M17 agar, $48 \%$ were lactococci (Torres-Llanez et al., 2006). The LAB counts in Mexican Fresco cheese made from raw milk reached 7.5 $\log \mathrm{cfu} / \mathrm{g}$ after a 10-d refrigerated storage, thus LAB abundance suggested that this type of flora might play an important role on the sensory characteristics of the product (Torres-Llanez et al., 2006). Although wild $L$. lactis strains may play a predominant role in Mexican Fresco cheese typical characteristics, the role of Lacto-

Table 1. Composition and physicochemical parameters for cheese milk and Mexican Fresco cheeses ${ }^{1}$

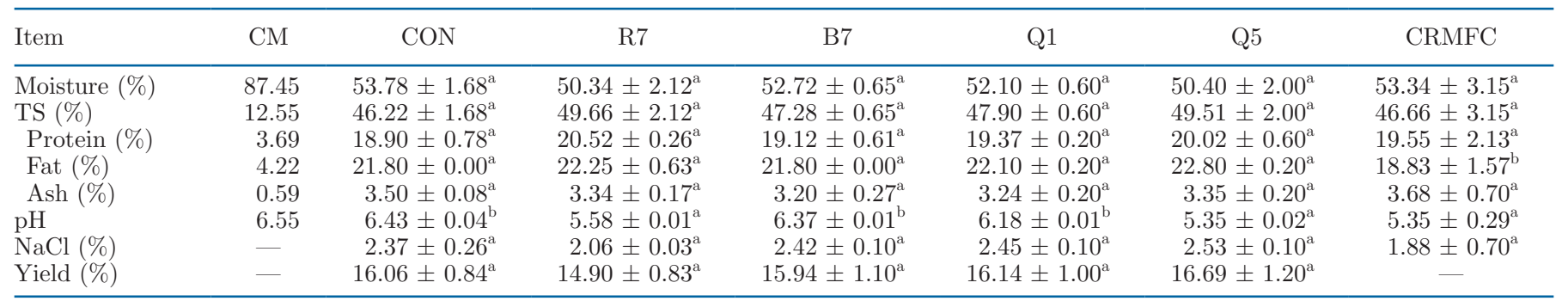

\footnotetext{
${ }^{\mathrm{a}, \mathrm{b}}$ Means within the same row with different superscripts are significantly different $(P<0.05)$.

${ }^{1} \mathrm{CM}=$ cheese milk; CON $=$ control Fresco cheese; R7, B7, Q1, Q5 = Fresco cheese with R7, B7, Q1, or Q5 starter culture; CRMFC = com-
} mercial raw milk Fresco cheese (average from 6 different commercial samples). Results represent means \pm SD $(n=4)$, CRMFC $(\mathrm{n}=6)$. 
bacillus spp., which is the next most numerous genus present as reported by Torres-Llanez et al. (2006), should not be disregarded.

\section{Sensory Analysis}

Mexican Fresco cheese aroma was described as milkfat, yogurt, yeasty, barny, and dirty socks. In addition, Fresco cheese was included as a general descriptor to let the panel give a score referred to the typical CRMFC aroma. Aroma intensity scores for CON, R7, B7, Q1, Q5, and CRMFC cheeses are depicted in a radial graph (Figure 1). These data indicated that CON and Q1 showed similar scores in most descriptors, except for the yogurt descriptor where Q1 had the highest score of all cheeses. Both were characterized with high scores for milkfat, although low in yeasty, barny, dirty socks, and Fresco cheese. Likewise, R7, B7, and Q5 showed similar aroma profiles in all descriptors and were characterized with high scores for Fresco cheese and milkfat, followed by yeasty and yogurt, but low scores for barny and dirty socks. On the other hand, CRMFC showed the highest scores for Fresco cheese, yeasty, and milkfat, followed by yogurt, dirty socks, and barny. According to the aroma profiles, R7 and B7 were similar to CRMFC in all descriptors, except for milkfat. Thus, these strains may have potential to be used as starter cultures for Mexican Fresco cheese made from pasteurized milk.

\section{Analysis of Volatile Compounds by SPME and GC-MS}

Volatiles in the different Mexican Fresco cheeses are shown in Table 2. A total of 61 volatile compounds were identified: 16 esters, 13 acids, 12 alcohols, 12 ketones, and 8 aldehydes. Total volatile abundances for samples are also shown in Table 2. As expected, the lowest total volatile abundance was found in the CON cheese with a total of $22.56 \pm 1.02(\mathrm{SD}) \mu \mathrm{g} / \mathrm{g}$, and was not different $(P>0.05)$ from Q5 $(23.25 \pm$ $0.59 \mu \mathrm{g} / \mathrm{g})$ and B7 $(25.68 \pm 1.25 \mu \mathrm{g} / \mathrm{g})$ cheeses. Nevertheless, B7 was not significantly different $(P>0.05)$ from CRMFC. Meanwhile, total volatile abundances for Q1 $(89.74 \pm 5.68 \mu \mathrm{g} / \mathrm{g}), \mathrm{R} 7(149.3 \pm 5.68 \mu \mathrm{g} / \mathrm{g})$, and CRMFC $(31.46 \pm 4.74 \mu \mathrm{g} / \mathrm{g})$ were significantly different $(P<0.05)$ among them (Table 2$)$. The largest number of esters, FAME such as butanoic, hexanoic, octanoic, and decanoic, were found in both CRMFC

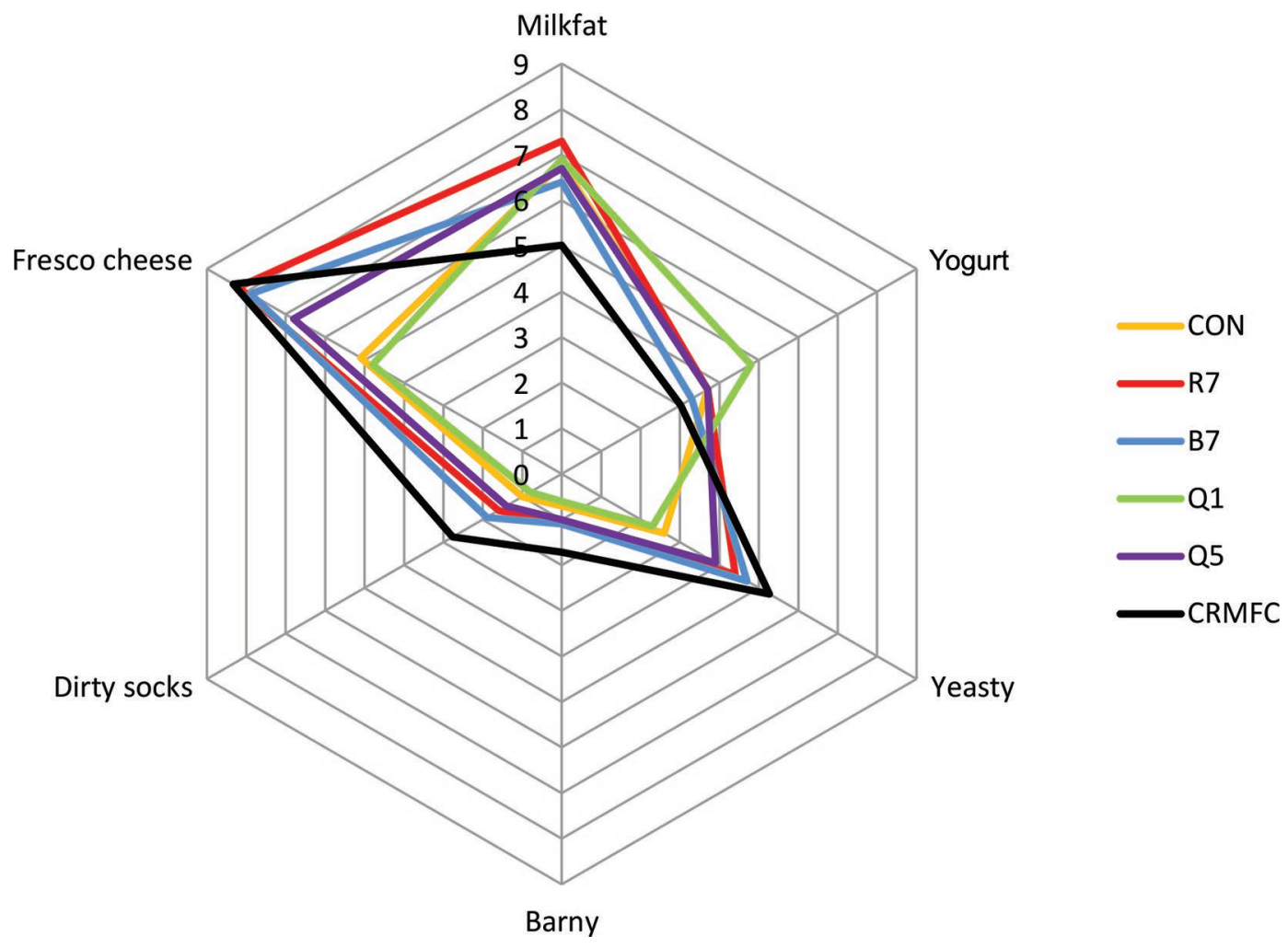

Figure 1. Radial graph of the aroma scores for Mexican Fresco cheeses determined by a trained sensory panel. CON $=$ control Fresco cheese; R7, B7, Q1, Q5 = Fresco cheese with R7, B7, Q1, or Q5 starter culture. CRMFC = commercial raw milk Fresco cheese (average from 6 different commercial samples). Results represent means $(\mathrm{n}=4)$, CRMFC $(\mathrm{n}=6)$. 
and R7. Nevertheless, these compounds were present in most cheeses, except in Q1 since it only showed the last 2. Also, heptanoic and 4-decenoic FAME were only found in R7. Moreover, heptanoic acid ethyl ester was produced in all cheeses except in CRMFC (Table 2). Ethyl esters were the most common esters reported in other cheeses (Thierry et al., 2017). Nevertheless, in this study FAME were the most abundant in Mexican Fresco cheese. Likewise, FAME and ethyl esters were also reported in Xinotyri cheese (Bontinis et al., 2012). In fact, these kind of compounds have been responsible for very pronounced fruity and floral notes, mainly attributed to ethyl esters (Wilkinson, 2007; Qian and Burbank, 2007; van Mastrigt et al., 2018). Although fruity or floral notes were not recorded in these cheese samples and in spite of esters, being the largest number of volatiles, those notes might have been masked by other more intense aromas.

Esters are formed in a reaction between an alcohol and an organic acid, which may also be activated by CoA. Besides AA metabolism, sugar and fat metabolism also provide substrates for ester formation (Yvon and Rijnen, 2001; Smit et al., 2005).

Carboxylic acids were the second largest group with 13 identified volatiles. These compounds may play an important role in aroma because most of them, except 4-methyl-2-oxovaleric and dodecanoic acid, were produced in most cheeses (Table 2). Six acids (butanoic, hexanoic, heptanoic, octanoic, nonanoic, and n-decanoic) were detected in all cheeses. The R7 and Q5 showed the largest number of acids, followed by CRMFC, Q1, and B7. Lactic acid bacteria have shown production of carboxylic acids in cheese as a result of their lipolytic activity (Ávila et al., 2007; Randazzo et al., 2008) or via glycolysis and proteolysis (Ganesan and Weimer, 2007). The conversion of lactose (glycolysis) mainly leads to the formation of lactate by $\mathrm{LAB}$, but a fraction of the intermediate pyruvate can alternatively be converted to various aroma compounds (Smit et al., 2005). Also, bacteria may use proteins in cheese and are metabolized to peptides and AA, which are the metabolic precursors of volatile compounds such as aldehydes, carboxylic acids, alcohols, and esters (Yvon and Rijnen, 2001; Smit et al., 2005).

In this work, commercial calf rennet was used to emulate the traditional cheese manufacture process of CRMFC. Thus, protein degradation in cheeses with $L$. lactis may take place not only by the proteolytic activity of the starter cultures, but also by the activities of the rennet enzymes. Nevertheless, a control cheese without L. lactis starter but containing the rennet enzymes in the commercial calf rennet used was also prepared. Indeed, it has been reported that protein degradation by the activities of rennet enzymes in ad- dition to cell-envelope proteinase and peptidases from LAB yields small peptides and free AA that may also be flavor precursors (Smit et al., 2005).

The presence of acids in Mexican Fresco cheese may play an important role in aroma production because they have been reported as possible precursors of esters, methyl ketones, and secondary alcohols (Engels et al., 1997). Acids can confer different notes, for example, they may impart aromas like vinegar, sour, pungent, rancid, cheesy, sweaty, sharp, fatty, and soapy (Qian and Burbank, 2007). The largest concentration of isovaleric acid (3-methyl-butanoic acid) was found in CRMFC and absent in CON. Nevertheless, it was produced in cheeses containing L. lactis strains (Q1, R7, and Q5), but at lower concentrations than in CRMFC. In fact, these cheese samples presented aroma notes like dirty socks, barny, and Fresco cheese, although with lower intensity scores than in CRMFC (Figure 1). This compound was reported to be associated with dirty socks (Delahunty and Drake, 2004), sweaty, fecal, barny (Singh et al., 2003), and cheese-like descriptors (Cadwallader and Singh, 2009).

Moreover, hexanoic acid was found at the highest concentration of all acids in R7. Also, this cheese presented high intensity for the Fresco cheese aroma descriptor (Figure 1). This compound was reported to elicit a goaty aroma in dairy products (Delahunty and Drake, 2004) and also cheesy and sharp notes (Ganesan and Weimer, 2007) that may be strongly related to the Fresco cheese aroma.

Alcohols represent the third largest group with 12 compounds (Table 2). Ethanol, 3-methyl-1-butanol and phenylethyl alcohol were found in most cheeses. It is important to note that CRMFC contained all 12 different alcohols, meanwhile CON only had ethanol and cheeses with starters (R7, B7, Q1, and Q5) showed some of these compounds. Interestingly, these cheeses had Fresco cheese and yeasty aroma notes that may be associated with these alcohols (Figure 1). In fact, 3-methyl-1-butanol has been found to confer aroma of fresh cheese in Mozzarella cheese (Amárita et al., 2006) and ethanol has been associated with a yeasty note (Cadwallader and Singh, 2009). Alcohols can generate a wide variety of aromas in cheese, for example, alcoholic, fruity, green, floral, rose, malty, honey, herbaceous, sweet, fragrant, caramel, and others (FernándezGarcía, 1996; Moio et al., 2000; Qian and Reineccius, 2002; Frank et al., 2004; Garde et al., 2005; Qian and Burbank, 2007; van Leuven et al., 2008). While alcohols may have only limited roles in the aroma of hard cheeses, they are important for the formation of esters, which have a much greater contribution to aroma (Vítová et al., 2006; Qian and Burbank, 2007). This may explain the presence of few alcohols in comparison to 
Table 2. Volatile compounds identified in Mexican Fresco cheese by headspace solid-phase microextraction and GC-MS ${ }^{1}$

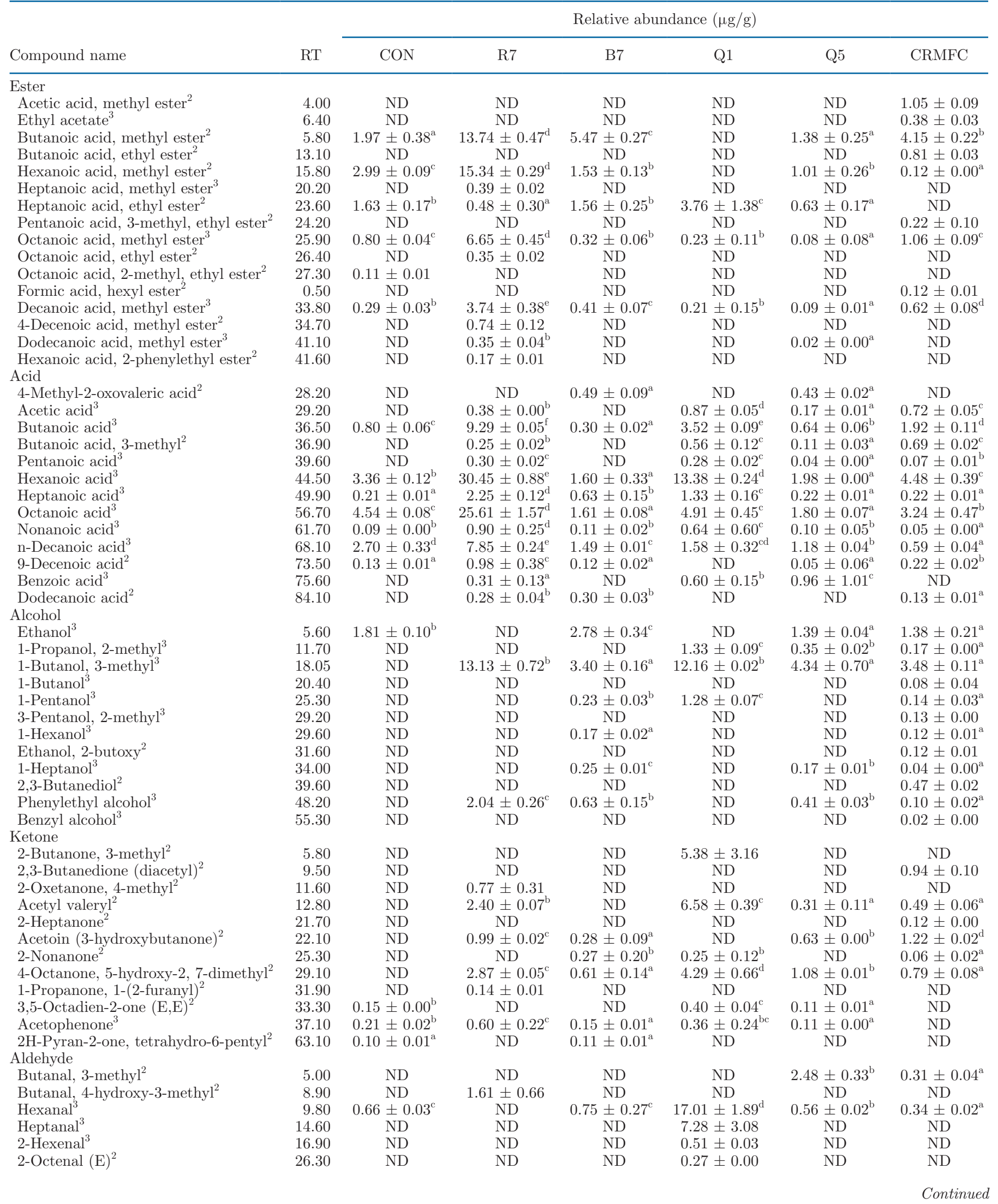


Table 2 (Continued). Volatile compounds identified in Mexican Fresco cheese by headspace solid-phase microextraction and GC-MS ${ }^{1}$

\begin{tabular}{|c|c|c|c|c|c|c|c|}
\hline Compound name & $\mathrm{RT}$ & \multicolumn{6}{|c|}{ Relative abundance $(\mu \mathrm{g} / \mathrm{g})$} \\
\hline $\begin{array}{l}\text { 2,4-Heptadienal }(\mathrm{E}, \mathrm{E})^{2} \\
\text { Benzaldehyde }^{3} \\
\text { Total abundance }^{4}\end{array}$ & $\begin{array}{l}29.60 \\
31.20\end{array}$ & $\begin{array}{c}\text { ND } \\
\text { ND } \\
22.56 \pm 1.02^{\mathrm{a}}\end{array}$ & $\begin{array}{c}\text { ND } \\
3.90 \pm 0.00^{\mathrm{c}} \\
149.23 \pm 5.68^{\mathrm{d}}\end{array}$ & $\begin{array}{c}0.12 \pm 0.05^{\mathrm{b}} \\
\mathrm{ND} \\
25.68 \pm 1.25^{\mathrm{ab}}\end{array}$ & $\begin{array}{c}0.76 \pm 0.10^{\mathrm{c}} \\
\mathrm{ND} \\
89.74 \pm 5.68^{\mathrm{c}}\end{array}$ & $\begin{aligned} 0.07 & \pm 0.00^{\mathrm{a}} \\
0.37 & \pm 0.02^{\mathrm{b}} \\
23.25 & \pm 0.59^{\mathrm{a}}\end{aligned}$ & $\begin{array}{c}\text { ND } \\
0.12 \pm 0.06^{\mathrm{a}} \\
31.46 \pm 4.74^{\mathrm{b}}\end{array}$ \\
\hline
\end{tabular}

${ }^{\mathrm{a}-\mathrm{f}}$ Different superscripts in the same row indicate significant differences $(P<0.05)$.

${ }^{1} \mathrm{CON}=$ control Fresco cheese; R7, B7, Q1, Q5 = Fresco cheese with R7, B7, Q1, or Q5 starter culture; CRMFC = commercial raw milk Fresco cheese; $\mathrm{RT}=$ retention time $(\mathrm{min}) ; \mathrm{ND}=$ not detected. Results represent means $\pm \mathrm{SD}(\mathrm{n}=4), \mathrm{CRMFC}(\mathrm{n}=6)$ of relative abundances $(\mu \mathrm{g} / \mathrm{g})$ referred to nonanoic acid, ethyl ester. $\mathrm{E}$ and $\mathrm{E}, \mathrm{E}$ indicate trans isomers with 1 or 2 double bonds, respectively.

${ }^{2}$ Volatile compound identified by GC-MS only.

${ }^{3}$ Volatile compound identified by both GC retention time of a standard compound and GC-MS.

${ }^{4}$ Total abundance $=$ total relative abundances $(\mu \mathrm{g} / \mathrm{g})$ of volatiles identified in samples.

the presence of several esters in cheese samples R7, B7, Q1, and Q5.

Alcohols are mainly derived from 3 major metabolic pathways: lactose catabolism, lipid catabolism, and protein catabolism (Qian and Burbank, 2007). Primary straight-chain alcohols are originated from the action of alcohol dehydrogenase on the aldehyde-products of fatty acid and AA metabolism in microbes (Qian and Burbank, 2007). Some alcohols, such as ethanol, 1-hexanol, 2-methyl-1-propanol, and 3-methyl-1-butanol, may originate from the corresponding aldehydes produced from some AA following a reaction pathway involving aminotransferases and alcohol dehydrogenases (Engels et al., 1997; Yvon and Rijnen, 2001; van Leuven et al., 2008). Several microorganisms that are able to produce alcohols in cheeses are lactococci, lactobacilli, and yeast (Yvon and Rijnen, 2001).

Twelve ketones were produced in Mexican Fresco cheese (Table 2). Acetyl valeryl, acetoin (3-hydroxybutanone), acetophenone, and 4-octanone 5-hydroxy-2,7dimethyl were produced in most cheeses. Moreover, acetophenone was found at low concentrations in all cheeses made from pasteurized milk (CON, R7, B7, Q1, and Q5) but absent in commercial cheeses made from raw milk (CRMFC; Table 2). It has been reported that acetophenone is produced during milk heat treatment as a result of Strecker degradation of phenylalanine and methylglyoxal (O'Brien, 2009). Thus, in this study, the presence of these volatiles in cheeses made from pasteurized milk may be due to the heat treatment applied. Also, acetoin was related to milkfat aroma notes in dairy products (Le Bars and Yvon, 2008). Indeed, in these cheese samples, milkfat aroma notes were recorded that may be attributed to the presence of acetoin (Figure 1).

Diacetyl (2,3-butanedione) and 2-heptanone were only produced in CRMFC, but were not produced in cheeses with the starter cultures. These volatiles are produced from the metabolism of citrate and were reported to be key aroma compounds in yogurt (Tian et al., 2019). Diacetyl also imparts notes related to the milkfat descriptor such as creamy and buttery (Le Bars and Yvon, 2008) and 2-heptanone has been related to the yogurt's sweet flavor and blue cheese-like note (Cadwallader and Singh, 2009; Tian et al., 2019).

Citrate fermentation in lactococci is of great industrial importance because it is related to the production of important odor compounds like diacetyl, acetaldehyde, and acetoin. In fact, in previous work, it was reported that all these wild lactococci strains were positive for citrate fermentation (Gutiérrez-Méndez et al., 2008). It is noteworthy to highlight that the L. lactis strains used as starter cultures in these cheeses produced acetoin, but did not produce diacetyl.

The R7, Q1, and CRMFC showed the most number of ketones (6), followed by B7 (5) and Q5 (5). It has been reported that these compounds confer different aromas in cheese, mainly buttery and creamy, associated with the milkfat descriptor. In fact, all these cheese samples, including CRMFC, displayed high intensity for the milkfat aroma descriptor (Figure 1). Besides, it was also reported that they may confer spicy, citrus, acetone-like, pungent, floral, fruity, and herbaceous notes (Moio et al., 2000; Garde et al., 2005; Qian and Burbank, 2007; van Leuven et al., 2008; van Mastrigt et al., 2018). Nevertheless, none of these aroma notes were detected in these cheeses.

Finally, 8 aldehydes were identified in samples, from which only hexanal was produced in most cheeses (Table 2). The Q1 contained the largest number of different aldehydes (5), followed by Q5 (4), CRMFC (3), R7 (2), and B7 (2). These compounds were reported to give notes like yogurt, caramel, creamy, unripe, applelike, cheesy, boiled potato, floral, waxy, pungent, malty, cocoa, pungent, grassy, green, waxy, woody, leafy, citrus, almond, and honey (Moio et al., 2000; Garde et al., 


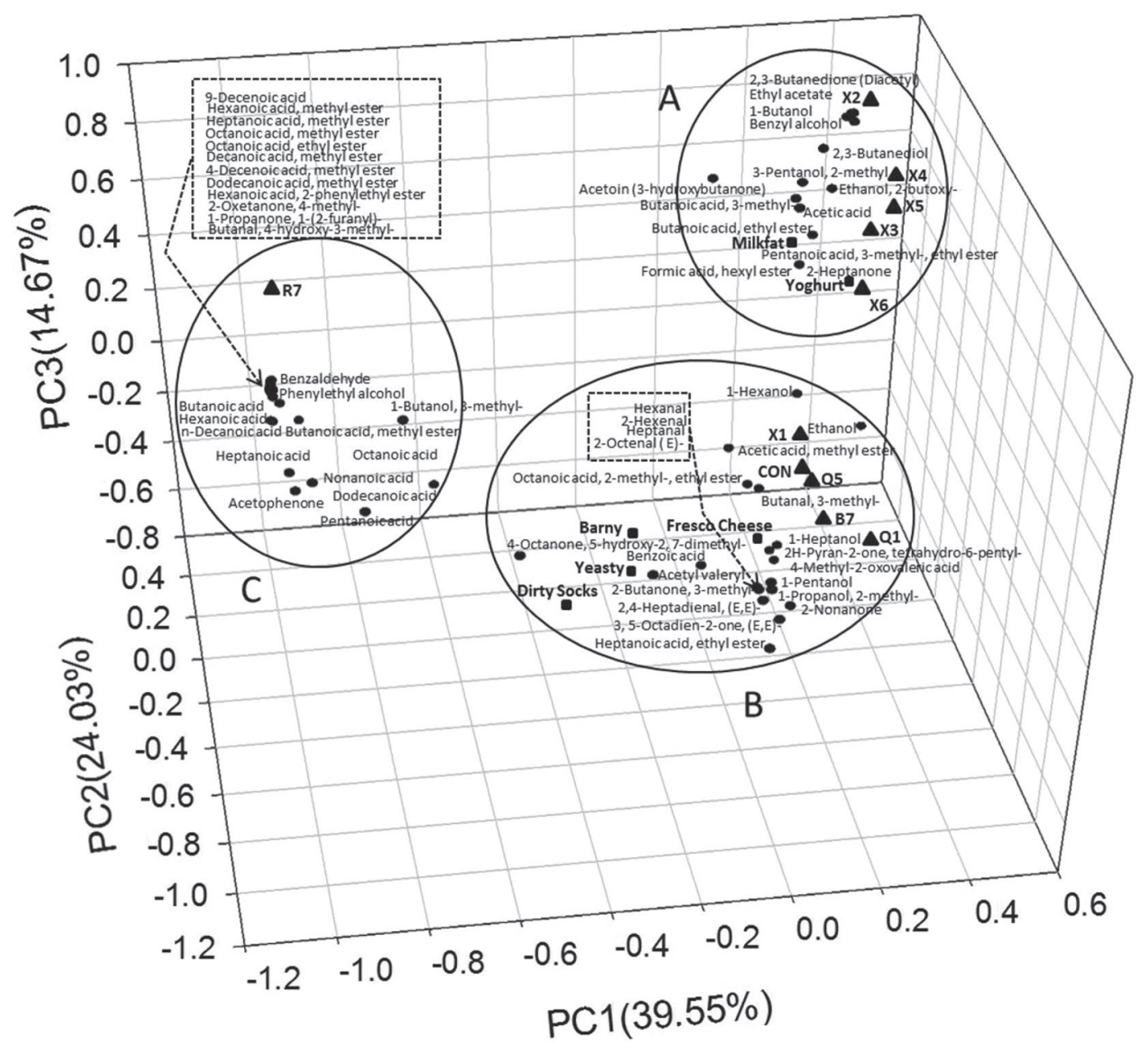

Figure 2. Principal component (PC) analysis of the first 3 factor scores and factor loadings of volatile compounds identified in Mexican Fresco cheese by headspace solid-phase microextraction and GC-MS. A, B, and CON: clusters determined by k-means cluster analysis. CON: control Fresco cheese; R7, B7, Q1, Q5: Fresco cheese with R7, B7, Q1, or Q5 starter culture; X1-X6: commercial raw milk Mexican Fresco cheeses. Milkfat, yogurt, yeasty, barny, dirty socks, Fresco cheese: aroma descriptors for Mexican Fresco cheese.

2005; Qian and Burbank, 2007; van Leuven et al., 2008; van Mastrigt et al., 2018). In fact, all cheese samples had yogurt aroma notes (Figure 1). Interestingly, Q1 showed the strongest intensity for the yogurt aroma descriptor that might be associated with its largest number of different aldehydes and highest concentrations of hexanal and heptanal of all (Table 2).

Aldehydes are products of fatty acids that arise from reduction reactions attributable to aldehyde dehydrogenases from bacteria. Also, they are derived from branched-chain AA catabolism (Ganesan and Weimer, 2007; Gobbetti et al., 2007).

\section{Principal Component Analysis}

Principal component analysis was applied to interpret how the 61 volatiles and 6 sensory descriptors discriminated among cheese samples. Figure 2 shows the factor scores of the samples and the factor loadings of the volatiles and sensory descriptors for the 3 first principal components (PC1, PC2, and PC3) with 39.5, 24.03 , and $14.67 \%$, respectively, which accounted for $78.25 \%$ of the total variation. Three main groups were identified: group A contained Mexican Fresco cheese commercial samples (X2-X6); group B contained one commercial cheese sample (X1), CON, B7, Q1, and Q5; and group C only contained R7. The PCA of the volatiles also showed a clear distinction among sample groups.

Group A, where samples X2-X6 (commercial cheese samples manufactured from raw milk) were located, clustered aroma volatiles (acetoin, diacetyl, and 2,3-butanediol) associated with the citrate metabolism mainly shown by citrate-positive lactococci and lactobacilli. 
Moreover, alcohols clustered in this same group may be produced by microorganisms in cheese such as lactococci, lactobacilli, and yeasts (Yvon and Rijnen, 2001); these microorganisms were reported to be present in the natural microflora of artisanal Mexican Fresco cheese made from raw milk (Torres-Llanez et al., 2006). Some of the volatiles in group A such as 2,3-butanedione (diacetyl) and 3-hydroxybutanone (acetoin) have been related to creamy and buttery notes in yogurt (Tian et al., 2019) and are associated with the milkfat descriptor also located in this group. Moreover, 2-heptanone, 1-butanol, ethyl acetate, and 3-methyl-butanoic acid (isovaleric acid) and the yogurt descriptor were also located in this group. These volatiles were reported to be typical compounds in yogurt (Cheng, 2010).

Group B, where sample X1 (commercial cheese sample manufactured from raw milk) and samples B7, Q1, and Q5 were located, clustered mainly aldehydes, ketones, and alcohols that may be the result of the catabolism of AA (Cadwallader and Singh, 2009). Barny, yeasty, dirty socks, and Fresco cheese descriptors were also associated with this group. 3-Methyl butanal found in this group has been reported to be the degradation product from leucine and was associated with malty notes (Cheng, 2010; Afzal et al., 2017). Thus, it is possible that malty notes may be associated with the yeasty descriptor.

Group C that only allocated sample R7, clustered mainly carboxylic acids, and esters. Interestingly, R7 showed the highest concentration for butanoic, hexanoic, heptanoic, octanoic, nonanoic, n-decanoic acids, and 9-decenoic acids of all. These compounds may be originated from the lipolysis of milkfat or from breakdown of AA. Butanoic acid was reported to impart cheesy, rancid, sweaty, dirty socks, and sour notes (Cheng, 2010; Kilcawley, 2017). Likewise, hexanoic, octanoic, and decanoic acids were also associated with rancid notes as well as other notes (Cheng, 2010). Pentanoic acid has been linked to dirty socks aroma (Laor et al., 2008). Benzaldehyde and phenylethyl alcohol derived from the catabolism of phenylalanine (Smid and Kleerebezem, 2014) were associated with bitter almond and floral notes, respectively. A key aroma compound in Fresco cheese was reported to be linked to the presence of 3-methyl-1-butanol as a result of the catabolism of leucine (Smit et al., 2005). This compound clustered in the $\mathrm{C}$ group and was at its highest concentration in R7, followed by Q1 and Q5. Also, this compound was in B7 and CRMFC in similar concentrations (3.40 \pm 0.16 and $3.48 \pm 0.11 \mu \mathrm{g} / \mathrm{g}$, respectively) and not found in the CON cheese.

The fact that R7 was in a different group and separate from the rest, was probably due to its highest volatile abundance of all, nevertheless it presented strong Fresco cheese aroma followed by milkfat, yeasty, yogurt, dirty socks, and barny aromas that are typical of raw milk Mexican Fresco cheese. It has been reported that flavor compounds produced by L. lactis mainly derive from AA catabolism, with transamination as the first step in the process catalyzed by aminotransferases AraT and BcaT with $\alpha$-ketoglutarate as the $\alpha$-ketoacid acceptor (Smid and Kleerebezem, 2014). In previous studies, it was reported that these L. lactis dairy strains were highly acidifying and proteolytic (Q1 > Q5 > R7) and the nondairy strain B7 was weakly acidifying and proteolytic in fermented milk (Rodríguez-Figueroa et al., 2010). Moreover, it was reported that these strains imparted intense Fresco cheese-like aroma for the dairy strains and intense yogurt-like aroma for the nondairy strain in fermented milk and were all confirmed glutamate dehydrogenase positive, which may be a criteria for the selection of flavor-producing strains (GutiérrezMéndez et al., 2008).

\section{CONCLUSIONS}

Mexican Fresco cheese-like aroma was described as milkfat, yogurt, yeasty, barny, dirty socks, and Fresco cheese, which are desirable notes since they typify these cheeses. According to the sensory panel, R7 and B7 were most similar to CRMFC in all descriptors. Nevertheless, the presence of the volatile, 3-methyl-1-butanol associated with Fresco cheese aroma may be one of the key compounds that determine L. lactis strain suitability for aroma production, without disregarding the importance of other key compounds associated with other aroma notes. Cheese made with L. lactis $\mathrm{R} 7$ was classified in the same group as key compounds associated with Fresco cheese aroma and show potential as a starter in Mexican Fresco cheese manufacture. Nevertheless, further work may be necessary to optimize the performance of L. lactis $\mathrm{R} 7$ in terms of dose rates or synergy (or both) with an adjunct culture in Mexican Fresco cheese manufacture. Thus, the selection of wild strains with specific technological and aroma characteristics such as L. lactis R7 may maintain Mexican Fresco cheese typicity.

\section{ACKNOWLEDGMENTS}

The authors thank the National Council for Science and Technology (Consejo Nacional de Ciencia y Tecnología, CONACyT) of Mexico for the graduate scholarship to Ricardo Reyes-Díaz. The technical assistance of María de Jesús Torres-Llanez is gratefully acknowledged. 


\section{REFERENCES}

Afzal, M. I., K. A. Boulahya, M. Jacquot, S. Delaunay, and C. Cailliezgrimal. 2017. Biosynthesis and role of 3 -methylbutanal in cheese by lactic acid bacteria: Major metabolic pathways, enzymes involved, and strategies for control. Crit. Rev. Food Sci. Nutr. 57:399-406.

Amárita, F., M. de la Plaza, P. Fernández de Palencia, T. Requena, and C. Peláez. 2006. Cooperation between wild lactococcal strains for cheese aroma formation. Food Chem. 94:240-246.

AOAC International. 2000. Official Methods of Analysis. 17th ed. AOAC Int., Gaithersburg, MD.

Ávila, M., J. Calzada, S. Garde, and M. Nuñez. 2007. Effect of a bacteriocin-producing Lactococcus lactis strain and high-pressure treatment on the esterase activity and free fatty acids in Hispánico cheese. Int. Dairy J. 17:1415-1423.

Ayad, E. H. E., A. Verheul, C. de Jong, J. T. M. Wouters, and G. Smit. 1999. Flavour forming abilities and amino acid requirements of Lactococcus lactis strains isolated from artisanal and non-dairy origin. Int. Dairy J. 9:725-735.

Aydin, C. M. 2017. Formation of volatile and non-volatile compounds in cheese. Int. J. Sci. Technol. Res. 6:252-263.

Bontinis, Th. G., H. Mallatou, E. C. Pappa, Th. Massouras, and E. Alichanidis. 2012. Study of proteolysis, lipolysis and volatile profile of a traditional Greek goat cheese (Xinotyri) during ripening. Small Rumin. Res. 105:193-201.

Cadwallader, K. R., and T. K. Singh. 2009. Flavours and off-flavours in milk and dairy products. Chapter 14, pages $631-690$ in Advanced Dairy Chemistry. Lactose, Water, Salts and Minor Constituents. Vol. 3, 3rd ed. P. L. H. Mc. Sweeney and P. F. Fox, ed. Springer Science + Business Media, LLC 2009, New York, NY.

Cheng, H. 2010. Volatile flavor compounds in yogurt: A review. Crit. Rev. Food Sci. Nutr. 50:938-950.

Delahunty, C. M., and M. A. Drake. 2004. Sensory character of cheese and its evaluation. Chapter 19, pages $455-487$ in Cheese: Chemistry, Physics and Microbiology. General Aspects. Vol. 1, 3rd ed. P. F. Fox, P. L. H. McSweeney, T. M. Cogan and T. P. Guinee, ed. Elsevier, London, UK.

Engels, W. J. M., R. Dekker, C. de Jong, R. Neeter, and S. Visser. 1997. A comparative study of volatile compounds in the watersoluble fraction of various types of ripened cheese. Int. Dairy J. $7: 255-263$.

Fernández-García, E. 1996. Use of headspace sampling in the quantitative analysis of artisanal Spanish cheese aroma. J. Agric. Food Chem. 44:1833-1839.

Fox, P. F., T. P. Guinee, T. M. Cogan, and P. L. H. McSweeney. 2017. Chemistry of milk constituents. Pages 71-104 in Fundamentals of Cheese Science. Springer, Boston, MA.

Frank, D. C., C. M. Owen, and J. Patterson. 2004. Solid phase microextraction (SPME) combined with gas-chromatography and olfactometry-mass spectrometry for characterization of cheese aroma compounds. Lebensm. Wiss. Technol. 37:139-154.

Ganesan, B., and B. C. Weimer. 2007. Amino acid metabolism in relationship to cheese flavor development. Pages 70-101 in Improving the flavour of cheese. B. C. Weimer, ed. CRC Press, Boca Raton, FL, and Woodhead Publishing Limited, Cambridge, England.

Ganesan, B., and B. C. Weimer. 2017. Amino acid catabolism and its relationship to cheese flavor outcomes. Pages 483-516 in Cheese: chemistry, physics, and microbiology. 4th ed. P. L. H. McSweeney, P. F. Fox, P. D. Cotter, and D. W. Everett, ed. Academic Press, San Diego, CA.

Garde, S., M. Ávila, M. Medina, and M. Nuñez. 2005. Influence of a bacteriocin-producing lactic culture on the volatile compounds, odour and aroma of Hispánico cheese. Int. Dairy J. 15:1034-1043.

Gobbetti, M., M. de Angelis, R. Di Cagno, and C. G. Rizzello. 2007. The relative contributions of starter cultures and non-starter bacteria to the flavour of cheese. Pages 121-156 in Improving the Flavour of Cheese. B. C. Weimer, ed. CRC Press, Boca Raton, FL, and Woodhead Publishing Limited, Cambridge, England.

González-Córdova, A. F., C. Yescas, A. Ortiz-Estrada, M. A. de la Rosa-Alcaraz, A. Hernández-Mendoza, and B. Vallejo-Cordoba.
2016. Invited review: Artisanal Mexican cheeses. J. Dairy Sci. 99:3250-3262.

Gutiérrez-Méndez, N., B. Vallejo-Cordoba, A. F. González-Córdova, G. V. Nevárez-Moorillón, and B. Rivera-Chavira. 2008. Evaluation of aroma generation of Lactococcus lactis with an electronic nose and sensory analysis. J. Dairy Sci. 91:49-57.

Hintze, J. 2006. NCSS, PASS, and GESS, NCSS, Kaysville, UT.

Kilcawley, K. N. 2017. Cheese Flavour. Chapter 13, pages 443-474 in Fundamentals of Cheese Science. 2nd ed. P. F. Fox, T. P. Guinee, T. M. Cogan, and P. L. H. McSweeney, ed. Springer, Boston, MA.

Laor, Y., J. A. Koziel, L. S. Cai, and U. Ravid. 2008. Chemical-sensory characterization of dairy manure odor using headspace solid-phase microextraction and multidimensional gas chromatography mass spectrometry-olfactometry. J. Air Waste Manag. Assoc. 58:11871197.

Le Bars, D., and M. Yvon. 2008. Formation of diacetyl and acetoin by Lactococcus lactis via aspartate catabolism. J. Appl. Microbiol. 104:171-177.

Marth, E. H. 1978. Standard Methods for the Examination of Dairy Products. 14th ed. American Public Health Association, Washington, DC.

Meilgaard, M., G. V. Civille and B. T. Carr. 1999. Sensory Evaluation Techniques. CRC Press, Boca Raton, FL.

Moio, L., P. Piombino, and F. Addeo. 2000. Odour-impact compounds of Gorgonzola cheese. J. Dairy Res. 67:273-285.

O'Brien, J. 2009. Non-enzymatic degradation pathways of lactose and their significance in dairy products. Pages 231-294 in Advanced Dairy Chemistry. Lactose, Water, Salts and Minor Constituents. Vol. 3. 3rd ed. P. L. H. McSweeney and P. F. Fox, ed. Springer Science + Business Media, LLC, New York, NY

Picon, A., O. López-Pérez, E. Torres, S. Garde, and M. Nuñez. 2019. Contribution of autochthonous lactic acid bacteria to the typical flavour of raw goat milk cheeses. Int. J. Food Microbiol. 299:8-22.

Qian, M., and G. Reineccius. 2002. Identification of aroma compounds in Parmigiano-Reggiano cheese by gas chromatography/olfactometry. J. Dairy Sci. 85:1362-1369.

Qian, M. C., and H. M. Burbank. 2007. Hard Italian cheeses: Parmigiano-Reggiano and Grana Padano. Pages 421-443 in Improving the Flavour of Cheese. Bart C. Weimer, ed. CRC Press, Boca Raton, FL, and Woodhead Publishing Limited, Cambridge, England

Randazzo, C. L., I. Pitino, S. de Luca, G. O. Scifò, and C. Caggia. 2008. Effect of wild strains used as starter cultures and adjunct cultures on the volatile compounds of the Pecorino Siciliano cheese. Int. J. Food Microbiol. 122:269-278.

Renye, J. A. Jr., G. A. Somkuti, B. Vallejo-Cordoba, D. L. van Hekken, and A. F. González-Córdova. 2008. Characterization of the microflora isolated from queso Fresco made from raw and pasteurized milk. J. Food Saf. 28:59-75.

Rodríguez-Figueroa, J. C., R. Reyes-Díaz, A. F. González-Córdova, R. Troncoso-Rojas, I. Vargas-Arispuro, and B. Vallejo-Cordoba. 2010. Angiotensin-converting enzyme inhibitory activity of milk fermented by wild and industrial Lactococcus lactis strains. J. Dairy Sci. 93:5032-5038.

Singh, T. K., M. A. Drake, and K. R. Cadwallader. 2003. Flavor of Cheddar cheese: A chemical and sensory perspective. Compr. Rev. Food Sci. Food Saf. 2:166-189.

Smid, E. J., and M. Kleerebezem. 2014. Production of aroma compounds in lactic fermentations. Annu. Rev. Food Sci. Technol. 5:313-326.

Smit, G., B. A. Smit, and W. J. M. Engels. 2005. Flavour formation by lactic acid bacteria and biochemical flavor profiling of cheese products. FEMS Microbiol. Rev. 29:591-610.

Thierry, A., Y. F. Collins, M. C. A. Mukdsi, P. L. H. McSweeney, M. G. Wilkinson, and H. E. Spinnler. 2017. Lipolysis and metabolism of fatty acids in cheese. Pages 423-444 in Cheese: Chemistry, Physics, and Microbiology. 4th ed. P. L. H. McSweeney, P. F. Fox, P. D. Cotter, and D. W. Everett, ed. Academic Press, San Diego, CA.

Tian, H., Y. Shi, Y. Zhang, H. Yu, H. Mu, and C. Chen. 2019. Screening of aroma-producing lactic acid bacteria and their application in improving the aromatic profile of yogurt. J. Food Biochem. 43:e12837. 
Torres-Llanez, M. J., B. Vallejo-Cordoba, M. E. Díaz-Cinco, M. A. Mazorra-Manzano, and A. F. González-Córdova. 2006. Characterization of the natural microflora of artisanal Mexican Fresco cheese. Food Control 17:683-690.

van de Bunt, B., P. A. Bron, L. Sijtsma, W. M. de Vos, and J. Hugenholtz. 2014. Use of non-growing Lactococcus lactis cell suspensions for production of volatile metabolites with direct relevance for flavour formation during dairy fermentations. Microb. Cell Fact. 13:176.

van Hekken, D. L., and N. Y. Farkye. 2003. Hispanic cheeses: The quest for queso. Food Technol. 57:32-38.

van Leuven, I., T. van Caelenberg, and P. Dirinck. 2008. Aroma characterisation of Gouda-type cheeses. Int. Dairy J. 18:790-800.

van Mastrigt, O., D. Gallegos, M. Kristensen, T. Abee, and E. J. Smid. 2018. Aroma formation during cheese ripening is best resembled by Lactococcus lactis retentostat cultures. Microb. Cell Fact. 17:104.

Vítová, E., B. Loupancová, J. Zemanová, H. Štoudková, P. Březina, and L. Babák. 2006. Solid-phase microextraction for analysis of mould cheese aroma. Czech J. Food Sci. 24:268-274.
Wilkinson, M. G. 2007. Lipolysis and cheese flavor development. Pages 102-120 in Improving the Flavour of Cheese. B. C. Weimer, ed. CRC Press, Boca Raton, FL, and Woodhead Publishing Limited, Cambridge, England.

Yvon, M., and L. Rijnen. 2001. Cheese flavour formation by amino acid catabolism. Int. Dairy J. 11:185-201.

\section{ORCIDS}

Aarón F. González-Córdova @ https://orcid.org/0000-0002-0674-4217 Miguel Angel Mazorra-Manzano @ https://orcid.org/0000-0002-1425 $-4250$

Belinda Vallejo-Cordoba @ https://orcid.org/0000-0001-8312-7039 